\title{
Culture, money attitudes and economic outcomes
}

\author{
Caroline Henchoz $^{1 *}$ D, Tristan Coste ${ }^{1}$ and Boris Wernli ${ }^{2}$
}

\begin{abstract}
Using novel survey data, we examine attitudes towards money and to what extent they affect economic outcomes in Switzerland. We find that three main types of attitudes towards money co-exist: the prestige and power attitude, the money management attitude and the goal-oriented attitude. The distribution of these attitudes differs across Switzerland's linguistic regions; all of them are more significant in the French-speaking part, compared to the German- and Italian-speaking parts of Switzerland.

Attitudes towards money shape financial behaviour, but the relationship varies depending on the type of financial behaviour. Culturally shaped attitudes to money are mostly linked with indebtedness; a finding that could help design better financial literacy programmes.

Keywords: Social values, Culture, Personal finance, Money, Education, Savings, Indebtedness

JEL-classification: A13, A14, D14, D83, 129
\end{abstract}

\section{Introduction}

In recent years, new data and techniques have made it possible to study the effects of culture, 'those customary beliefs and values that ethnic, religious, and social groups transmit fairly unchanged from generation to generation', on individual financial practices (Guiso, Sapienza, and Zingales, 2006, p. 23). A growing literature documents differences in financial decisions taken by individual members of cultural groups. In a study of 80,000 individuals from 76 countries around the world, Falk et al. (2015) address national cultures with regard to preferences relating to risk and time that influence a wide range of individual-level behaviours including savings and labour market choices (see also Carroll, Rhee, and Rhee, 1994, 1999). National culture also affects individual behaviours related to indebtedness and mortgages (Guiso, Sapienza, and Zingales, 2013) and to shopping behaviours (Gentina, Butori, Rose, and Bakir, 2013; Parker, Hermans, and Schaefer, 2008) or individual financial market investment behaviours (Chui, Titman, and Wei, 2010; Eun, Wang, and Xiao,

\footnotetext{
* Correspondence: caroline.henchoz@unifr.ch

1 Département des Sciences Sociales, Unité de Sociologie, University of

Fribourg, Bd de Pérolles 90, CH-1700 Fribourg, Switzerland

Full list of author information is available at the end of the article
}

2015; Grinblatt and Keloharju, 2001; Guiso, Sapienza, and Zingales, 2008).

'It is therefore likely that culture influences business and financial decisions' (Aggarwal, Faccio, Guedhami, and Kwok, 2016, p. 1), but it is nevertheless more difficult to know whether this influence is linked to different cultural attitudes towards money or the institutional, legal, political and social context specific to each country. Only a few, and recent, studies demonstrate the existence of different cultural attitudes towards money in a single national context (Medina, Saegert, and Gresham, 1996; Tang, Arocas, and Whiteside, 1997). As Kahneman, awarded the Nobel Prize in Economic Sciences in 2002, stated: 'much remains to be learned about the "endowment effect" of cultural differences in attitude towards money (Kahneman, 2011: 299). Little is yet known about the way in which cultural differences in attitude towards money affect economic outcomes (Mitchell and Mickel, 1999; Tang et al. 2015).

In this study, we document the link between cultural differences in attitude towards money and their potential impact on individual financial behaviours. Our analysis is based on an online survey of a representative sample of 1390 men and women aged between 18 and 30 years from Switzerland's three main linguistic regions (German, French and Italian). We begin by documenting the 
existence of the different attitudes towards money among our sample of the Swiss population and test how these are linked to the different linguistic regions. We then examine the extent to which these attitudes affect economic outcomes. This approach has the advantage of testing both the existence of a cultural relationship with money, and the possible influence of this relationship on individual financial behaviours.

Our research contributes to the literature on the meanings of money. As a number of scholars have argued, 'research on money, specifically, money as an individual difference variable-has been neglected' (Mitchell and Mickel, 1999, p. 568). We demonstrate that while a large majority of our population perceives money as a means to be autonomous, different money attitudes can co-exist even within a single national context. We distinguish three main types of attitude towards money: the prestige and power attitude, the money management attitude and the goal-oriented attitude. Our results confirm, as do other studies conducted in Switzerland (Brown, Henchoz, and Spycher, 2018), that different attitudes towards money indeed exist depending on the linguistic region (German, French or Italian). We show that the distribution of these three main attitudes differs across Switzerland's linguistic regions; all of the attitudes are adhered to more strongly by the survey respondents from the French-speaking region, compared to the Germanand Italian-speaking regions of Switzerland. We thus confirm that an understanding of cultural differences through language-an approach taken in other research (Eugster, Lalive, Steinhauer, and Zweimueller, 2017; Eugster, Lalive, Steinhauer, and Zweimüller, 2011; Eugster and Parchet, 2013) - is a pertinent one. Our study also contributes to the culture and finance literature by linking culture and economic outcomes. It identifies a relation between cultural attitudes towards money and financial practices. This relation must, however, be put into perspective. On the one hand, it varies depending on the type of practice in question. Our results show that the cultural attitudes towards money are linked, above all, to indebtedness. The link appears minimal regarding savings. On the other hand, only certain attitudes can be related to indebtedness. It is mainly when money is considered as a means to obtain prestige and power that the relation to the presence and type of debts becomes evident. Consequently, this study may also be highly relevant for policy-makers, notably with a view to applying financial literacy programmes more effectively. It concerns what Brown, Henchoz, and Spycher (2018) observed, i.e. the importance of developing financial education programmes that focus not only on improving financial skills and encouraging forward-looking behaviour, but also that integrate different predispositions within the target group; notably money attitudes.

\section{Swiss culture and economic outcomes}

Several studies on Switzerland demonstrate that there is a clear distinction between the linguistic groups in terms of work attitudes, voting behaviour, demand for social insurance, taxation or financial practices (Eugster et al. 2017; Eugster et al. 2011; Eugster and Parchet, 2013; Guin, 2017). Guin (2017) shows, for example, that considerable differences exist in behaviour associated with savings and indebtedness. Households in French-speaking regions save less than those in the German-speaking regions, and are more likely to take out formal credits and informal ones (among the family network, for example) in the case of financial difficulties and overdue payments. This is confirmed by the Federal Statistical Office (FSO); households in the French-speaking regions are ahead of the Italianand German-speaking Swiss in terms of indebtedness. ${ }^{1}$ Moreover, debts owed to the family or to friends are more common among the French-speaking Swiss than German speakers. ${ }^{2}$ The same tendency can be found among people aged 18-30 years. The existing literature suggests that French-speaking students save less (Guin, 2017). German-speaking people who leave the parental home have larger incomes, have fewer financial difficulties, save more and have fewer overdue payments than those in the other regions of the country (Wernli and Henchoz, 2015).

Two main theories have been advanced by economists to explain the origin of these cultural differences and their impact on financial practices. The first concerns different conceptions of the state. The more liberal vision of the state on the part of the German-speaking Swiss (Eugster et al. 2011; Eugster and Parchet, 2013) ${ }^{3}$ appears to lead them to rely on their own resources to a greater extent and thus to lend more importance to individual savings (Guin, 2017). The other theory relates to time preferences. The French-speaking Swiss, who are less patient (Guin, 2017), appear to be less prepared to wait and to delay their consumer choices until later. That could notably be explained via the syntax of the language (Chen, 2013; Sutter, Kocher, Glätzle-Rüetzler, and Trautmann, 2013); speakers of languages favouring the use of the future tense, as is the case for French, tend to be less patient than speakers of languages that make little use of the future tense, such as German.

These studies often use non-financial indicators-such as, in Switzerland, voting results (Eugster et al. 2011) or the consumption of cigarettes (Guin, 2017) - to explain different cultural behaviours (see also Aggarwal et al. 2016, pp. 3-4).

We do not have a great deal of information on cultural attitudes towards money in Switzerland. In a recent study comparing students aged 15 in a narrow geographic region along the German-French language border within the Swiss Canton of Fribourg, Brown et al. (2018) focused on certain items that we have developed in our study. They observed that French-speaking 
students connect money more strongly with freedom. However, they note that the lower level of financial literacy on the part of the French-speaking Swiss than that of their German-speaking counterparts could be explained more by their lower level of financial socialisation (e.g. they have less pocket money or are less likely to have an own bank account) then by different cultural attitudes towards money.

\section{Data and methodology}

Our analysis is based on an online survey elaborated within the framework of sociological research funded by the Swiss National Science Foundation. This research uses a mixedmethods approach to study financial socialisation among young people in Switzerland. ${ }^{4}$ The objective of the online survey was to consolidate and generalise the hypotheses established in the qualitative phase (Bühlmann and Tettamanti, 2007; see also Creswell, 2009). It had three major themes: (i) attitudes and values linked to money; (ii) financial practices (savings, management of money and consumption); (iii) indebtedness (type, extent and reasons for the debts). It was based on a raw sample of 5000 persons aged between 18 and 30 years residing in Switzerland. The sample was taken at random among the three linguistic regions (German, French and Italian) ${ }^{6}$ with an intended over-weighting of those from the Italian-speaking region (10\%).

The survey was held from May to July 2015, with contact by post (a first mailing and one reminder), inviting the respondents to complete an online questionnaire. ${ }^{7}$ We obtained a response rate of $28 \%$ ( $15 \%$ with the first mailing), which represented 1390 completed questionnaires. ${ }^{8}$ The quality of the responses was particularly high, because the dropout rate was only 1\% (50 questionnaires) and the item 'nonresponse' was virtually non-existent for all the 1390 questionnaires completed. Because of their convenient format and their interactivity, a key advantage of web surveys is precisely their ability to produce high-quality data (Schaefer and Dillman, 1998).

\subsection{Items measuring the components of attitudes towards money}

The most popular scale to measure money attitudes is Tang's Money Ethical Scale (MES), which has been used in over 50 countries (Tang, Furnham, and Davis, 2003, p. 177). Depending on the version, it has between 12 and 30 items that evaluate three components of the MES; the affective component (good and bad), the behavioural component (budget) and the cognitive component (accomplishment, respect and power) (Tang, Furnham, and Davis, 2002; Tang et al. 2003). It has above all been used to determine the extent to which the cultural meaning of money had an impact on work-related attitudes, e.g. job and pay satisfaction (Tang et al. 2002, 2003) and consumer practices (Vitell, Paolillo, and Singh, 2006; Vitell, Singh, and Paolillo, 2007).
We have not used this scale in full in our questionnaire for two main reasons. First, it cannot test the explanatory hypotheses arising from the qualitative part of the research in a satisfactory way. Second, we consider that it has the disadvantage of mixing attachment to certain values associated with money and the evaluation of one's own financial behaviour. Consequently, we retained the cognitive component of the MES (see Table 1, questions $1-4)$. To these, we have added two other attributes associated with money and that are the result of sociology studies on the social meaning of money (Lamont, 1992; Zelizer, 2005) (question 5) and research on materialism (Richins, 2004; Richins and Dawson, 1992) (question 6).

We also retained the behavioural component of the MES (questions 7-10). In our survey, this second group of instruments measuring attitudes towards money is related to parental transmissions associated with the uses of money, i.e. the values that have been transmitted regarding the appropriate way of using one's financial resources. We considered it important to evaluate the money attitudes learned through the socialisation process established in childhood and that relate to ways of acting, because it has been demonstrated that these aspects influence adult behaviour (Argyle and Furnham, 1998; Furnham, Kirkcaldy, and Lynn, 1994). Moreover, parents are considered to play a decisive role in teaching attitudes towards money (Beutler and Dickson, 2008).

\subsection{Organisation of the article, hypotheses and methods}

In the first part of the analysis, we describe the distribution of the responses related to the cognitive and behavioural component of attitudes towards money among our respondents. We base this on the hypothesis, taken from the qualitative exploratory study by Dell'Orto and Doyle (2001) on 'Meanings of money in Italy and in Switzerland'. According to this study, Swiss people have an analytical relation with money, unlike Italians, who exhibit the 'expressive' trait, spending money freely for themselves and for friends and 'using wealth to judge worth, linking money, or the lack of it, to potency, compassion, ethics. [While] the Swiss shun [...] money as inappropriate, thus restricting its emotional value' (Dell'Orto and Doyle, 2001, p. 260). According to these authors, the Swiss personify the 'analytic' and 'driver' types; they rank 'save' or 'invest' the highest. Money is understood as an end in itself rather than as a means. On this basis, we could expect that the majority of our respondents would attribute a low score to the cognitive attributes associated with money (items 1-5) except where money is seen to be a purpose in itself (item 6), which should obtain a high score. This also applies to the behavioural component related to money. Behaviours associated with savings, management of money and solvency (items 8-10) should obtain a higher score than the item related to pleasure (item 7). 
Table 1 The 10-dimensional instrument measuring attitudes towards money

\begin{tabular}{lll}
\hline I. Cognitive component & Item: 'to what extent do you agree with the following phrases:' \\
& 5-point Likert scale: (1) strongly disagree; (2) disagree; (3) neither agree nor disagree; (4) \\
& agree; (5) strongly agree
\end{tabular}

In the second part, we identify the main attitudes towards money in Switzerland. According to Tang (1992, p. 201), people's attitudes towards money can be defined 'as their 'frame of reference' in which they examine their everyday lives' and that they use to take the related financial decisions. To identify 'frames of reference, we use principal component analysis (PCA). ${ }^{9}$ PCA allows us to select the components of attitudes towards money from the first part of the study which have the highest correlations with the principal component, thus structuring the information collected from the respondents. By identifying latent factors, this technique (Kim and Mueller, 1978) reveals the structure subjacent to the indicators measured (Table 1) and permits representation along distinct axes. In order to retain only the principal components, which are the dimensions where there is the most variance in the dataset, we use the Kaiser criterion to remove all components with eigenvalues under 1.0, thus ignoring all the secondary eigenvectors. An orthogonal rotation is used to maximise the variance of the squared loadings of a factor and to decorrelate the extracted components. Finally, factor scores are calculated using a linear combination (least squares regression) of the items loading on each factor. Under this process, the computed factor scores are standardised to a mean of zero, with a standard deviation of 1 .

In the third part, we tested the existence of different cultural attitudes towards money in Switzerland. According to literature cited previously, we supposed that there would be a link between the attitudes towards money shown in the second part and the language region. If that was the case, could we expect that the Italian-speaking Swiss would have an attitude closer to the Italian expressive trait highlighted by Dell'Orto and Doyle (2001) than that of the German and French-speaking Swiss?

A series of multilevel linear regressions (Hox, 2010) was used to model the positioning on the axis of continuous values that were identified after the PCA was carried out, according to a series of independent continuous or dichotomous variables. This method aims to test the hypothesis of a differentiated positioning on the value axes among our respondents depending on their socio-demographic characteristics. Multilevel models are needed in that case because data from the same Swiss canton are generally more similar to each other, due to the socio-economic, cultural and legal context, than data from different cantons, and this violates the assumption of independence of all observations made by the 'classical' ordinary least squares model. This kind of model can be expressed algebraically with the following linear multilevel equation (Eq. 1). $Y_{i c}$ refers to the score on the dependent variable for an individual (i) observed in his canton (c), $x_{1 i c}$ to the first predictor (ranging from 1 to $\mathrm{p}$ ) for an individual (i) observed in his canton (c), $\beta_{1}$ ((ranging from 1 to $p$ ) refers to the slope between the first predictor and the dependent variable, and $\gamma_{00}$ to the intercept of the dependent variable.

To take the non-independence of the observations inside the same canton into account, the residuals are subdivided into two parts. In addition to the varying error term for each observation ( $\varepsilon_{-}$ic), which is common to every regression equation, we add a second error term ( $\left.\mu \_0 c\right)$ that remains constant for all observations of the same canton. This approach allows us to structure the residuals and correlate them within cantons.

$$
\begin{aligned}
Y_{i c}= & {\left[\gamma_{00}+\beta_{1} \cdot x_{1 i c}+\beta_{2} \cdot x_{2 i c}+\ldots+\beta_{p} \cdot x_{p i c}\right] } \\
& +\left[\mu_{0 c}+\varepsilon_{i c}\right],
\end{aligned}
$$

where $c=$ canton and $i=$ individual and where $u_{0 c} \sim N(0$, $\left.\tau_{u 0}\right)$ and $\varepsilon_{i c} \sim N\left(0, \tau_{e}\right)$.

In the fourth part, we study the association between money attitudes and outcomes, as measured by previous research (Carroll, Rhee and Rhee, 1994, 1999; Khare, 2015; 
Roberts and Jones, 2001). We consider two economic outcomes: savings and debts. As we have seen in Section 2, it is above all these two aspects of financial behaviour that have been used in research conducted in Switzerland to evaluate cultural differences. We model various different financial practices related to these behaviours, i.e. regular savings, having a debt, having overdue bills or having leasing contracts, using multilevel binary logistical regression analyses (Goldstein, 1991). This tool is appropriate because of the dichotomous character of our dependent variables; the explanatory factors could be either continuous or dichotomous variables, and take into account the existing correlation between data gathered in the same Swiss canton. Equation 2 looks similar to a 'classical' logistic regression model, with the inclusion of a supplementary term ( $\left.\mu \_0 c\right)$ which remains constant for all the observations of the same canton and allows us to make the intercept of our logit ( $\left.\beta \_00\right)$ vary for each canton.

$$
\operatorname{Pr}\left(y_{i c}=1\right)=\frac{1}{1+e^{-\left(\beta 00+\beta_{1} x_{1 i c}+\beta_{2} x_{2 i c}+\ldots+\beta_{p x_{p i c}}+\mu 0_{c}\right)}},
$$

where $c=$ canton and $i=$ individual and where $u_{0 c} \sim N\left(0, \tau_{u 0}\right)$.

\section{Results}

\subsection{Cognitive and behavioural attitudes towards money}

Figure 1 partially confirms our hypotheses based on the exploratory study by Dell'Orto and Doyle (2001). In general, Swiss people do have a relation with money that can be qualified as analytical. Only $28 \%$ strongly agree or agree with the fact that money is a means to have power (item 4), $21 \%$ attribute a value of social recognition to money (item 2), and only $8 \%$ agree with the fact that money is a means to make friends (item 5). Nevertheless, and contrary to the results by Dell'Orto and Doyle (2001), money is rarely perceived as an end in itself. Only $9 \%$ of the respondents were partially or fully in agreement with the fact that it was something they were prepared to achieve by any means (item 6). The principal cognitive components of attitude towards money that emerge from the analysis can be brought together under the concept of autonomy; the majority of the respondents see money as freedom and achievement. For $79 \%$ respondents, money is seen as a means to do what they enjoy (47\% agree partially and 32\% agree strongly with this statement-item 3 ), and for $71 \%$, money is a means to achieve objectives $(51 \%$ are partially in agreement and $20 \%$ are strongly in agreement with this statement-item 1).

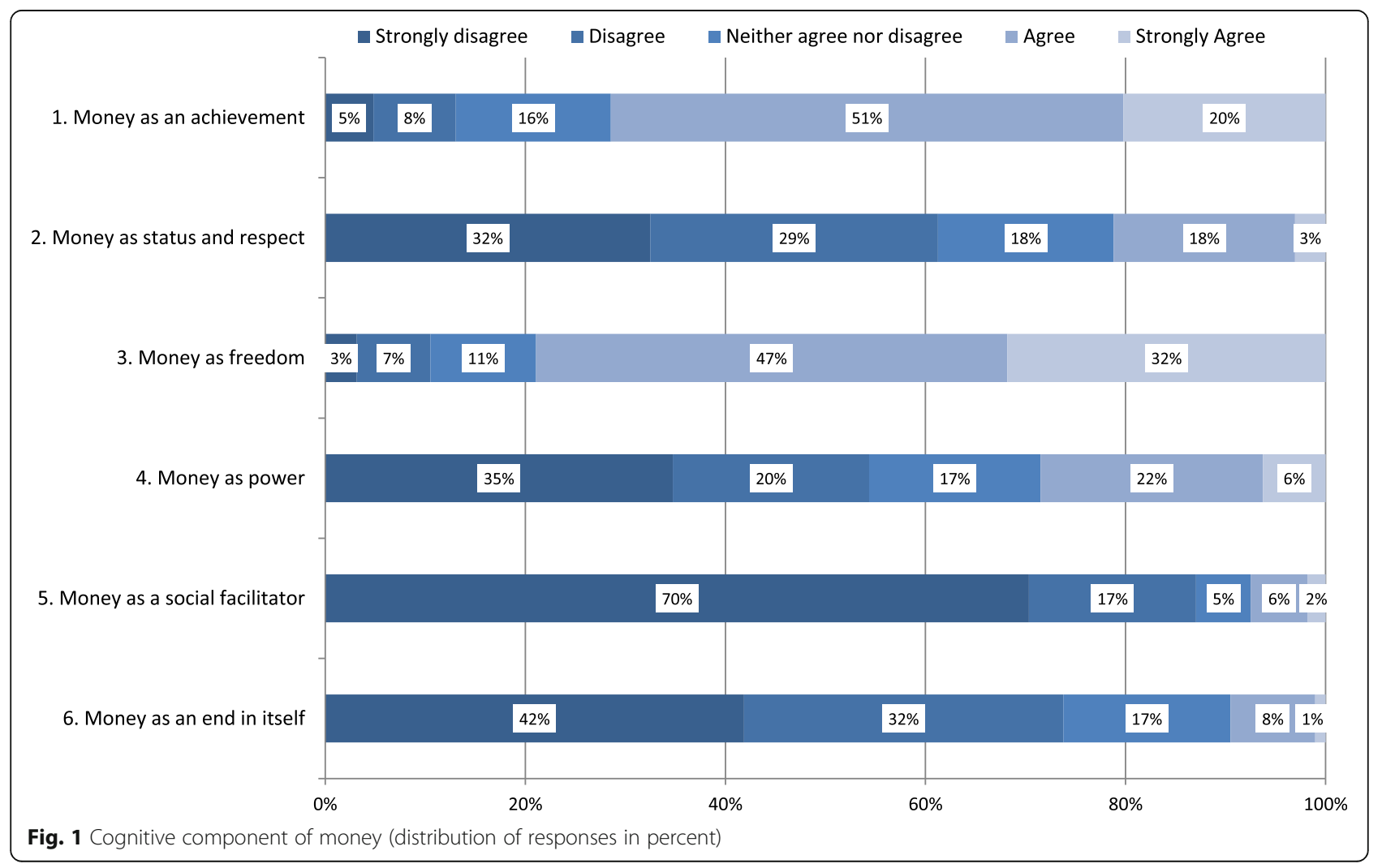


Figure 2 confirms the strong attachment to the behaviour of savings, balanced budgeting and solvency (items $8-10)$. The values transmitted by the parents aim to inculcate a certain degree of moderation and a 'spirit of being economical' that the sociologist Boltanski (1966) had already identified in the Swiss population of the 1960s. According to him, 'Swiss virtues are fully expressed in the opposition between the serious and the futile-a dichotomy that is valid for all situations of existence' (translation) (Boltanski, 1966, p. 24). Even now, nearly $88 \%$ of respondents affirm that when they were children or adolescents, their parents often or very often told them that one should never spend more money than one has (item 9), $81 \%$ were told that it was necessary to put money aside (item 8), and $75 \%$ were told that one should never enter into debt (item 10). Conversely, using money for enjoyment is only mentioned by $19 \%$ (item 7 ).

\subsection{Attitudes towards money in Switzerland}

By distinguishing 3 out of the 10 indicators presented in Figs. 1 and 2, the PCA confirms the hypothesis of the co-existence of different attitudes towards money in Switzerland. ${ }^{10}$ These three main attitudes towards money can be defined as follows. The first money attitude identified (axis 1), the 'prestige and power attitude', is only defined by cognitive dimensions related to social connections, social prestige and power linked to money, which is consistent with the money attitude scale (Yamauchi and Templer, 1982). The axis of prestige-power is strongly linked to the items in line with this topic. The indicator of money as status and respect is correlated at 0.81 ; money as power is at 0.76 , while the items related to money as an end in itself (0.57) and money as a social facilitator $(0.55)$ are related to a lesser extent.

The second money attitude (axis 2), the 'economical management attitude', is only defined by the behavioural component, which seems to us to be associated with money management in accordance with the spirit of being economical and serious, already observed by Boltanski (1966). The items attached to balanced-type, solvency and savings-oriented behaviour are correlated to a more or less equal extent (0.82, 0.79 and 0.76 , respectively) to axis 2 .

The third money attitude identified (axis 3 ), the 'goal-oriented attitude', is a mix between cognitive and behavioural dimensions but all of them are goal-oriented. Axis 3 is associated with money as freedom (0.70); with money as an achievement (0.66) and with money as a means to enjoy oneself (hedonist behaviour) (0.60) (Table 2).

\subsection{Cultural attitudes towards money}

The results presented in Table 3 confirm the existence of different money attitudes in Switzerland depending on linguistic region. The linguistic region is the unique parameter that systematically and significantly influences the three value axes. Compared to the German-speaking Swiss, the Frenchspeaking Swiss have higher scores on the prestige-power axis $(0.28)^{11}$ and on the goal-oriented axis (0.18). They also have higher scores on the economical management axis $(0.18)$. The Italian-speaking Swiss have a lower score on the goal-oriented axis $(-0.56)$ than the German-speaking Swiss (which means that they cannot be associated with the Italian

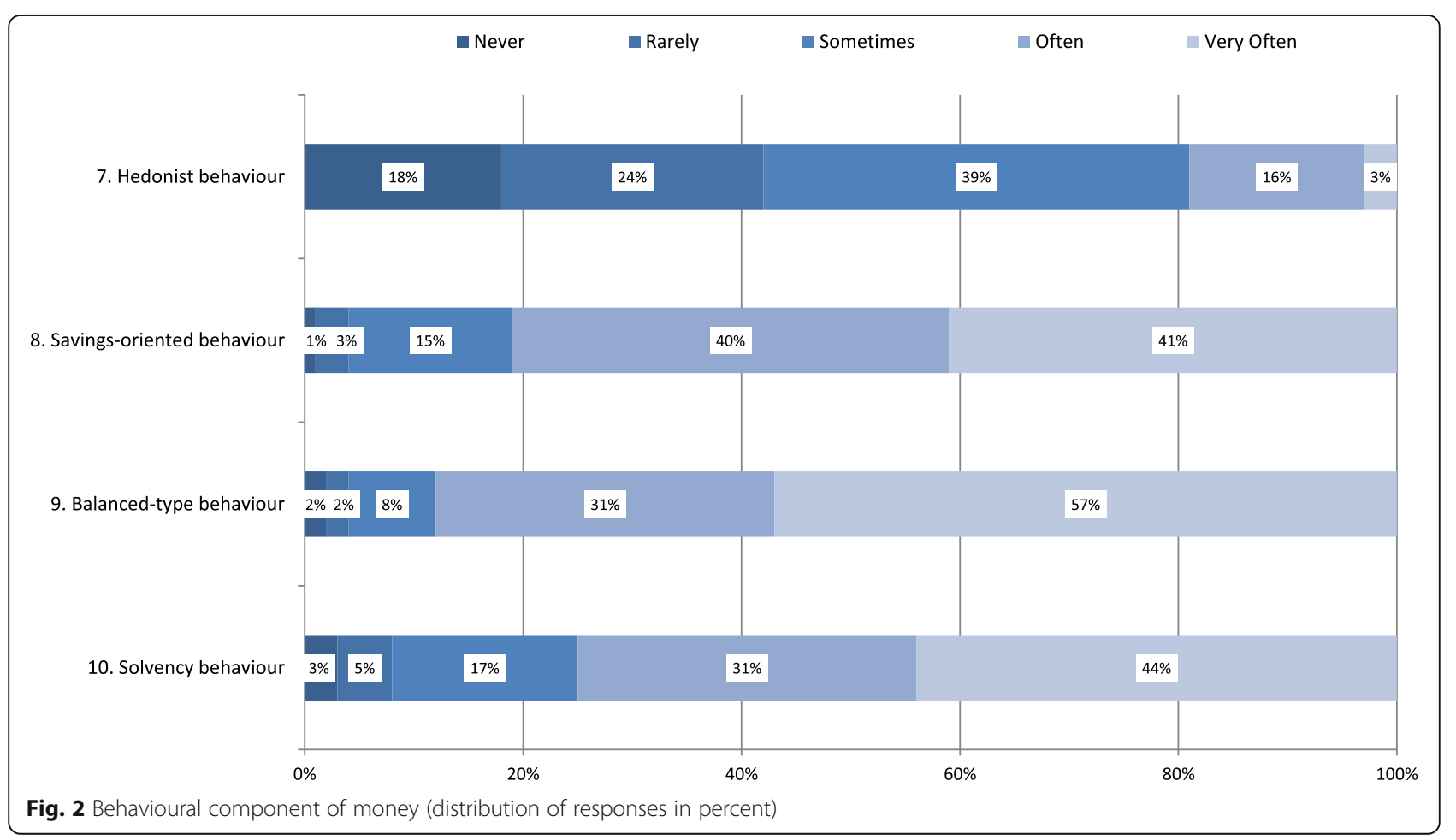


expressive type of Dell'Orto and Doyle, 2001). While this result confirms the hypothesis of the existence of cultural attitudes towards money, we do not find that each linguistic region has its own cultural attitude. We can interpret this result in light of the work of Polanyi ([1944] 1983). In the German- and Italian-speaking regions of Switzerland, attitudes towards money seem more disembedded from their social dimensions than in the French-speaking region. Prestige and power attitude, economical management attitude and goal-oriented attitude all received less support. The Germanand Italian-speaking Swiss seem to grant fewer attributes to money than the French-speaking Swiss, as if money was more seen and perceived in its instrumental perspective.

The significant but less systematic impact of several other parameters should also be noted. The prestigepower attitude is more often adopted by men $(0.28)$ than by women. One possible explanation can be found in the 'breadwinner role' that is assumed by the majority of men in Switzerland (Mosimann, 2016) and which implies that part of the social recognition they can expect is the result of their capacity to assume this role successfully (Henchoz, 2008). Foreigners (- 0.22 for the Swiss) are also more represented on the prestige-power axis, which tends to confirm the presence of cultural attitudes towards money. Higher scores on this axis are also shown by those with higher incomes ( 0.42 for revenues of CHF 7000 per month and above) and those who live with their two parents, while those living as a couple without children are less sensitive (-0.24).

The economical management attitude towards money seems distributed throughout the population, since no variation emerged based on the variables examined, with one exception. More people with intermediate education clearly adhere to this attitude (0.26) than those with elementary or higher education. This result confirms a qualitative study carried out in the Canton of Fribourg on money uses and attitudes among apprentices and students of vocational high schools, universities of applied science and universities (Henchoz, 2013a, 2013b). The former appear to attach considerable importance to saving money. This is confirmed in the present study by the fact that individuals with intermediate-level education are less represented among the goal-oriented attitude.

\subsection{Association between attitudes and outcomes}

The results of the multilevel binary logistical regression analyses presented in Table 4 confirm our hypotheses; culturally different money attitudes can be related to different financial practices, but the link depends on the economic outcome examined.

No money attitude significantly influences the savings behaviours, ${ }^{12}$ which confirms the results by Carroll et al. (1994, 1999); cultural money attitudes seem to have no significant effects on savings. In our case, this result can be attributed to the fact that saving is a behaviour largely practised by our respondents $(69.9 \%$ of them usually put money aside every month, see Fig. 2) and more generally by the entire Swiss population (OECD, 2015). Inversely, we observe a significant relation between attitudes towards money and indebtedness, and between the type of debts (overdue bill(s) or leasing). ${ }^{13} \mathrm{~A}$ high score on the prestige-power attitude axis increases the tendency to contract debts (odds ratio of 1.16) and to have overdue bill(s) (1.22), which is consistent with our hypotheses and with earlier research on compulsive buying (Roberts and Jones, 2001; Roberts and Sepulveda, 1999). From another angle, the fact of being sensitive to economical management attitudes diminishes the risks of having overdue bills

Table 2 Principal attitudes towards money

\begin{tabular}{|c|c|c|c|c|}
\hline & & $\begin{array}{l}\text { Axis 1: prestige-power } \\
\text { attitude }\end{array}$ & $\begin{array}{l}\text { Axis 2: economical } \\
\text { management attitude }\end{array}$ & $\begin{array}{l}\text { Axe 3: goal-oriented } \\
\text { attitude }\end{array}$ \\
\hline I. & Cognitive component & & & \\
\hline 1 & Money as an achievement & & & 0.66 \\
\hline 2 & Money as status and respect & 0.81 & & \\
\hline 3 & Money as freedom & & & 0.70 \\
\hline 4 & Money as power & 0.76 & & \\
\hline 5 & Money as a social facilitator & 0.55 & & \\
\hline 6 & Money as an end in itself (materialism) & 0.57 & & \\
\hline II. & Behavioural component & & & \\
\hline 7 & Hedonist behaviour & & & 0.60 \\
\hline 8 & Savings-oriented behaviour & & 0.76 & \\
\hline 9 & Balanced-type behaviour (keeping a balanced budget) & & 0.82 & \\
\hline 10 & Solvency behaviour (do not have any debts) & & 0.79 & \\
\hline
\end{tabular}

Note: Table 2 presents the factor loadings, meaning the correlation (Pearson's $r$ ) between each variable measured and the factors after their orthogonal rotation, thus making it possible to facilitate the interpretation. To better reveal the structure of the values associated with money, the table ignores the correlations below 0.30 and places the items in the order of Table 1 
Table 3 Positioning on the attitude axes—multilevel linear regression

\begin{tabular}{|c|c|c|c|c|c|c|}
\hline & \multicolumn{2}{|c|}{ Axis 1: prestige-power } & \multicolumn{2}{|c|}{ Axis 2: economical management } & \multicolumn{2}{|c|}{ Axis 3: goal-oriented } \\
\hline & Estimate & Sig. & Estimate & Sig. & Estimate & Sig. \\
\hline Sex: $0=$ woman, $1=$ man & .285 & .000 & -.102 & .093 & -.036 & .553 \\
\hline Age: $0=26-30$ years, $1=18-25$ years & -.054 & .473 & .142 & .064 & -.058 & .440 \\
\hline Nationality: $0=$ foreign, $1=$ Swiss & -.219 & .045 & -.121 & .291 & .190 & .093 \\
\hline Residence: $0=$ rural, 1 = urban & .132 & .845 & -.094 & .121 & .004 & .951 \\
\hline \multicolumn{7}{|l|}{ Linguistic region: ref. German-speaking } \\
\hline French-speaking region & .280 & .000 & .181 & .017 & .181 & .007 \\
\hline Italian-speaking region & .209 & .132 & .203 & .094 & -.558 & .000 \\
\hline \multicolumn{7}{|l|}{ Income level: ref. below CHF 1000 per month } \\
\hline From CHF 1000 to CHF 2000 per month & -.149 & .131 & -.103 & .307 & .096 & .336 \\
\hline From CHF 2001 to CHF 3000 per month & -.055 & .679 & -.071 & .602 & .098 & .470 \\
\hline From CHF 3001 to CHF 4000 per month & -.133 & .344 & .092 & .522 & .021 & .882 \\
\hline From CHF 4001 to CHF 5000 per month & -.001 & .994 & .051 & .724 & .010 & .947 \\
\hline From CHF 5001 to CHF 6000 per month & -.022 & .888 & .122 & .445 & .072 & .648 \\
\hline From CHF 6001 to CHF 7000 per month & .233 & .181 & -.050 & .779 & .030 & .864 \\
\hline From CHF 7001 to CHF 8000 per month & .420 & .036 & -.187 & .358 & .288 & .153 \\
\hline \multicolumn{7}{|l|}{ Composition of the household: ref. with two parents } \\
\hline With the mother & -.088 & .465 & -.079 & .522 & .168 & .167 \\
\hline Alone & -.167 & .109 & .027 & .802 & .077 & .460 \\
\hline As a couple & -.235 & .016 & .045 & .651 & .089 & .364 \\
\hline As a couple, with child(ren) & -.175 & .138 & -.037 & .761 & -.191 & .108 \\
\hline Other & -.172 & .066 & -.092 & .334 & .171 & .070 \\
\hline \multicolumn{7}{|l|}{ Level of education: ref. high (tertiary education) } \\
\hline Low (elementary education) & -.035 & .828 & -.106 & .515 & -.241 & .136 \\
\hline Medium (professional training) & .070 & .304 & .262 & .000 & -.162 & .019 \\
\hline \multicolumn{7}{|l|}{ Main activity: ref. in education } \\
\hline Working (full-time and part-time work) & -.126 & .301 & -.020 & .873 & .108 & .381 \\
\hline Other (unemployed, home management and disability) & .118 & .396 & .161 & .259 & .056 & .691 \\
\hline
\end{tabular}

(0.74), which we can explain by the fact that the individuals concerned probably have sufficient foresight to pay their bills in time. It is interesting, however, to note that this attitude does not have a link to savings, no doubt because - as we have already said-the practice of saving is widespread in Switzerland. It is also important to note that the goal-oriented attitude has no significant effect on either of the economic outcomes examined.

Although attitudes towards money can have a certain link to economic practices, we note that it is above all certain control variables that have a considerable effect. Income level has a strongly positive influence on the capacity to save, as does the composition of the household. Young people living with their two parents have a much higher savings capacity, which perhaps also explains why their propensity to incur debts, to have overdue bills or to take out leasing is much lower than that of those living alone or as a couple. We also note that a tertiary level of education considerably reduces the risks of contracting debt, taking out leasing or having overdue bills, which is consistent with the results of the study conducted by the FSO (Christin, 2012; Fleury and Christin, 2015).

Finally, we note the highly significant impact of the linguistic region on financial practices. Controlled using the other parameters examined, we note that inhabitants of the French-speaking region are clearly less inclined to save (odds ratio of 0.53 ), while the probability of them contracting a debt (1.62), taking out leasing (2.77) or having overdue bills (1.87) is higher than that of those in the German-speaking region. Those in the Italian-speaking region stand out because of the much higher propensity (5.78) to take out leasing. They also have a higher probability of contracting a debt (1.51) than those in the German-speaking region. These results point to 
Table 4 Multilevel binary logistical regression analyses for savings and indebtedness

\begin{tabular}{|c|c|c|c|c|c|c|c|c|}
\hline & \multicolumn{2}{|l|}{ Savings } & \multicolumn{2}{|l|}{ Debt } & \multicolumn{2}{|c|}{ Overdue bill(s) } & \multicolumn{2}{|l|}{ Leasing } \\
\hline & $\operatorname{Exp}(B)$ & Sig. & $\operatorname{Exp}(B)$ & Sig. & $\operatorname{Exp}(B)$ & Sig. & $\operatorname{Exp}(B)$ & Sig. \\
\hline Sex: $0=$ woman, $1=$ man & .650 & .000 & 1.070 & .676 & 1.001 & .996 & 1.011 & .973 \\
\hline Age: $0=26-30$ years, $1=18-25$ years & 2.005 & .000 & .631 & .007 & .679 & .141 & 1.075 & .807 \\
\hline Nationality: $0=$ foreign, $1=$ Swiss & 1.844 & .017 & .583 & .036 & .508 & .079 & .338 & .000 \\
\hline Residence: $0=$ rural, $1=$ urban & 1.026 & .845 & .781 & .098 & .932 & .679 & .975 & .922 \\
\hline \multicolumn{9}{|l|}{ Linguistic region: ref. German-speaking } \\
\hline French-speaking region & .529 & .000 & 1.617 & .000 & 1.868 & .001 & 2.770 & .000 \\
\hline Italian-speaking region & 1.200 & .132 & 1.510 & .000 & .841 & .340 & 5.779 & .000 \\
\hline \multicolumn{9}{|l|}{ Income level: ref. below CHF 1000 per month } \\
\hline From CHF 1000 to CHF 2000 per month & 1.697 & .003 & 1.372 & .148 & .871 & .684 & 1.634 & .538 \\
\hline From CHF 2001 to CHF 3000 per month & 1.826 & .013 & 1.092 & .789 & 643 & .370 & .876 & .867 \\
\hline From CHF 3001 to CHF 4000 per month & 4.496 & .000 & 1.400 & .161 & .519 & .220 & 3.032 & .275 \\
\hline From CHF 4001 to CHF 5000 per month & 7.614 & .000 & 1.198 & .602 & .506 & .279 & 2.920 & .239 \\
\hline From CHF 5001 to CHF 6000 per month & 16.433 & .000 & .702 & .342 & .538 & .391 & 2.909 & .265 \\
\hline From CHF 6001 to CHF 7000 per month & 74.339 & .000 & .549 & .078 & .098 & .000 & 1.552 & .684 \\
\hline From CHF 7001 to CHF 8000 per month & 28.492 & .000 & 1.021 & .965 & .427 & .238 & 2.874 & .296 \\
\hline \multicolumn{9}{|l|}{ Composition of the household: ref. with two parents } \\
\hline With the mother & .602 & .018 & 2.028 & .001 & 3.205 & .000 & 2.079 & .130 \\
\hline Alone & .196 & .000 & 2.865 & .000 & 2.422 & .007 & 4.612 & .002 \\
\hline As a couple & .245 & .000 & 2.228 & .000 & 1.178 & .732 & 2.171 & .004 \\
\hline As a couple, with child(ren) & .421 & .034 & 2.872 & .000 & .766 & .534 & 6.492 & .001 \\
\hline Other & .298 & .000 & 1.876 & .002 & 2.335 & .006 & 2.297 & .113 \\
\hline \multicolumn{9}{|l|}{ Level of education: ref. high (tertiary education) } \\
\hline Low (elementary education) & .560 & .185 & 1.577 & .341 & 3.140 & .001 & 6.557 & .003 \\
\hline Medium (professional training) & .926 & .774 & 1.713 & .001 & 2.279 & .004 & 4.261 & .001 \\
\hline \multicolumn{9}{|l|}{ Main activity: ref. in education } \\
\hline Working (full-time and part-time work) & 1.613 & .179 & .808 & .426 & 1.882 & .180 & 2.081 & .382 \\
\hline Other (unemployed, home management and disability) & 1.247 & .535 & 1.191 & .542 & 5.161 & .000 & .944 & .934 \\
\hline Axis 1: prestige-power attitude; standardised variable & 1.011 & .865 & 1.155 & .042 & 1.224 & .006 & 1.260 & .126 \\
\hline Axis 2: economical management attitude; standardised variable & 1.094 & .266 & .942 & .320 & .742 & .001 & .910 & .299 \\
\hline Axis 3: goal-oriented attitude; standardised variable & 1.082 & .218 & 1.059 & .387 & 1.046 & .589 & .884 & .206 \\
\hline
\end{tabular}

Note: Significant results ( $p$ value<.05) are in bold. Estimation method is MLE (maximum likelihood estimation). Variables are described in the Appendix

the existence of other cultural influences that were not integrated in the multilevel model, because we reiterate the fact that here, we address the net impact of the linguistic regions, controlled using the other parameters of the equation; notably the attitudes towards money, but also socio-economic values such as revenue, type of habitation, level of education or main activity and, most importantly, the canton-level effect. These other cultural influences can be linked to the two main theories mentioned at the beginning of the article on the cultural differences between the German-, French- and Italianspeaking Swiss: the vision of the state (Eugster et al. 2011, Eugster and Parchet, 2013) and the time preferences (Guin 2017). Consequently, our explanations do not invalidate previous explanatory theories but propose a complementary approach.

\section{Conclusion}

This study contributes to the culture and finance literature in several ways. First, it emphasises the strong homogeneity of meanings of money in Switzerland among young people. The majority of our respondents see money essentially as a means to reach their autonomy in terms of freedom, achievement and doing what they enjoy. They also express a strong attachment to savings, to being solvent and to having a balanced budget. This result can partly be explained by the fact that our study population is in a specific period of life 
marked by entering adulthood and access to financial independence (Galland, [1984] 2009; Henchoz, Plomb, Poglia Mileti, and Schultheis, 2016). This homogeneity is confirmed by the limited predictive capacity of the models. Given the low number of significant relationships and the low impact of the independent variables, the parameters considered in Table 3 globally account for a small part of the variation of the variables studied. In other words, few specific demographic characteristics distinguish the individuals who are closer to one or the other money attitudes identified (see Section 4.3).

Second, this research shows that despite this strong national homogeneity, different attitudes towards money nevertheless co-exist in Switzerland and that they are associated with the linguistic region but not in the manner we expected. Brown et al. (2018) already demonstrated that German-speaking students aged 15 years had a different attitude to money than their French-speaking counterparts, and we confirm this result in our present study. However, the three main attitudes towards money that emerge: prestige and power, economical management and a goal-oriented attitude, are all adhered to more strongly in the French-speaking region of Switzerland than in the German- and Italian-speaking regions. We interpret this result by the fact that the French-speaking Swiss seem to attribute more social significance to money. For them, money is more 'embedded' (Polanyi, [1944] 1983) in social relations and in status-related, power, management and goal issues than for German- and Italian-speaking Swiss, who seem to have a more instrumental perception of money.

Third, our research also contributes to the culture and finance literature by documenting the link between culture and economic outcomes. It identifies a relation between cultural attitude towards money and financial practices. It nevertheless also reveals that this relation varies depending on the type of practices concerned, which seems to confirm previous research on saving and credit card use (Carroll et al. 1994, 1999; Roberts and Jones, 2001; Roberts and Sepulveda, 1999). We show that there is, above all, a link with indebtedness. The prestige-power attitude can be related to the presence of debts and leasing contracts, and the economical management attitude has a negative impact on the presence of overdue bills.

These results also have a strong relevance for policy-makers, notably within the framework of financial literacy programmes. While financial literacy is intended to improve financial skills and encourage forward-looking behaviour while taking money attitudes and consumption into account, it is also necessary to construct programmes adapted to issues that are specific to differing cultural contexts, and that genuinely take into account the cultural, subjective attitude towards money.

\section{Endnotes}

${ }^{1}$ https://www.bfs.admin.ch/bfs/fr/home/statistiques/ situation-economique-sociale-population/revenus-consommation-et-fortune/endettement.html, table je-f-20.02.04.01

${ }^{2}$ https://www.bfs.admin.ch/bfs/fr/home/statistiques/situation-economique-sociale-population/revenus-consommation-et-fortune/endettement.html, table je-f-20.02.04.01.

${ }^{3}$ According to Eugster and Parchet (2013, p. 9), 'French-speaking respondents expressed stronger support for redistribution and social services, even at the expense of higher taxes' and Italian-speaking groups are more in favour of expansions of social insurance (Eugster et al. 2011).

${ }^{4}$ http://fns.unifr.ch/jeunes-et-argent/fr.

${ }^{5}$ Since the FSO no longer provides addresses for specific research projects, these were obtained from a private company (AZ Direct) that constitutes its own registers.

${ }^{6}$ As the basis for the determination of the linguistic regions, we use the municipality (commune) of residence. In our analysis, we make no distinction between the linguistic region and the language spoken by our respondents. The tests conducted on our respondents show that the linguistic region corresponds $98 \%$ to the two items of our questionnaire that are the language spoken and the language learned in secondary school. Thus, it is impossible to decorrelate these two variables (linguistic region and language) and the effect of one on the other cannot be identified.

${ }^{7}$ Containing around 50 items, the questionnaire took 20-25 min to complete and was available online in German, French and Italian.

${ }^{8}$ See Appendix for characteristics of respondents

${ }^{9}$ The PCA was the subject of an orthogonal rotation (complete decorrelation of the factors) in order to facilitate their interpretation and to make them more pertinent at the theoretical level. One thousand three hundred sixty-four cases are valid on all the variables, meaning only 26 cases lack one or the other $(2 \%)$.

${ }^{10}$ The Kaiser-Meyer-Olkin (KMO) coefficient of 0.68 shows that the summary of the 10 variables measured is a technically satisfactory solution, while the $52 \%$ variance explained by the three factors denotes their good representation of the global complexity of information.

${ }^{11}$ The three value axes are standardised variables (mean $=0$ and standard deviation $=1$ ). The French-speaking Swiss have 0.28 standard deviation more than the German-speaking Swiss, which is a high score.

${ }^{12}$ See Appendix for description of the variables.

${ }^{13} 31.5 \%$ of our respondents have debts; $11.2 \%$ have overdue bill(s) and $7.42 \%$ a leasing contract. 


\section{Appendix}

Table 5 Description of the variables

\begin{tabular}{|c|c|}
\hline Name & Description \\
\hline Savings & 'Savings' is made up of one binary item (yes/no): 'can you usually put money aside every month?' \\
\hline Debt & $\begin{array}{l}\text { 'Debt' is made up of nine binary items (yes/no): 'at the moment, do you have the following: } \\
\text { (i) one or several overdue bills; (ii) one or several overdrawn accounts; (iii) one or several negative balances } \\
\text { on your credit cards; (iv) a loan from a bank or an entity that provides small-scale credits; (v) a loan from } \\
\text { your family; (vi) a loan from your friends; (vii) leasing for a vehicle; (viii) instalments of a payment agreement } \\
\text { that are ongoing; (ix) a purchase on credit that is ongoing.' A single 'yes' on the part of a respondent is } \\
\text { sufficient for the individual to be considered as indebted/having a debt }\end{array}$ \\
\hline Overdue bill(s) & 'Overdue bill(s)' corresponds to item (i) of 'debt' \\
\hline Leasing & 'Leasing' corresponds to item (vii) of 'debt' \\
\hline Types of education & $\begin{array}{l}\text { 01) No school education } \\
\text { 02) Primary school } \\
\text { 03) Secondary school } \\
\text { 04) Elementary professional training } \\
\text { 05) Apprenticeship, professional training } \\
\text { 06) Vocational school } \\
\text { 07) Higher commercial school } \\
\text { 08) Professional baccalaureate } \\
\text { 09) School with baccalaureate exam. } \\
\text { 10) Higher professional training (with diploma) } \\
\text { 11) Higher technical/management school } \\
\text { 12) University of applied, teacher training } \\
\text { 13) University/polytechnic }\end{array}$ \\
\hline $\begin{array}{l}\text { Level of education } \\
\text { (low)—elementary education }\end{array}$ & Types of education (01-04) \\
\hline $\begin{array}{l}\text { Level of education } \\
\text { (medium)—Professional training }\end{array}$ & Types of education (05-11) \\
\hline $\begin{array}{l}\text { Level of education (high) — tertiary } \\
\text { education }\end{array}$ & Types of education (12-13) \\
\hline
\end{tabular}

Table 6 Characteristics of respondents

\begin{tabular}{lcc}
\hline & Percentage & Observations \\
\hline Sex & & 1386 \\
Woman & 58.10 & \\
Man & 41.90 & 1378 \\
Age & & \\
18-25 years & 47.30 & 1390 \\
26-30 years & 52.70 & 12 \\
Nationality & & 1390 \\
Foreign & 7.30 & 0 \\
Swiss & 92.70 & 1330 \\
Residence & & \\
Rural & 15.90 & \\
Urban & 84.10 & 60 \\
Linguistic region & & \\
German-speaking region & 62.10 & \\
French-speaking region & 25.60 &
\end{tabular}


Table 6 Characteristics of respondents (Continued)

\begin{tabular}{|c|c|c|c|}
\hline & Percentage & Observations & Missing \\
\hline Income level & & 1335 & 55 \\
\hline Below CHF 1000 per month & 21.30 & & \\
\hline From CHF 1000 to CHF 2000 per month & 15.50 & & \\
\hline From CHF 2001 to CHF 3000 per month & 9.10 & & \\
\hline From CHF 3001 to CHF 4000 per month & 13.20 & & \\
\hline From CHF 4001 to CHF 5000 per month & 20.30 & & \\
\hline From CHF 5001 to CHF 6000 per month & 10.70 & & \\
\hline From CHF 6001 to CHF 7000 per month & 6.20 & & \\
\hline From CHF 7001 to CHF 8000 per month & 3.70 & & \\
\hline Above CHF 8000 per month & - & & \\
\hline Composition of the household & & 1387 & 3 \\
\hline With two parents & 28.40 & & \\
\hline With the mother & 6.80 & & \\
\hline Alone & 14.90 & & \\
\hline As a couple & 22.10 & & \\
\hline As a couple, with child(ren) & 12.10 & & \\
\hline Other & 15.60 & & \\
\hline Level of education & & 1349 & 41 \\
\hline Low & 4.30 & & \\
\hline Middle & 64.60 & & \\
\hline High & 31.10 & & \\
\hline Main activity & & 1330 & 60 \\
\hline In education & 31.30 & & \\
\hline Working & 60.80 & & \\
\hline Other & 8.00 & & \\
\hline
\end{tabular}

\section{Acknowledgements}

The authors thank colleagues at the Fribourg University Department of Sciences des cultures, des sociétés et des religions, especially Laura Mellini for Italian translation of the survey. We also thank Nicolas Pekari (FORS/Unil) for technical assistance for Limesurvey and questionnaire design; Brenda Kübler for the English translation of the manuscript; Alexis Gabadinho for his participation in study conception; as well as participants at the 2016 AISLF International workshop for valuable comments. Last but not the least, we are grateful to Martin Brown and Thomas Spicher (St-Gallen University) for their interest and encouragements, Rafael Lalive and the anonymous reviewers of Swiss Journal of Economics and Statistics for their constructive suggestions and criticisms.

\section{Funding}

Swiss National Science Foundation.

\section{Availability of data and materials}

2019; Swiss Centre of Expertise in the Social Sciences (FORS).

\section{Authors' contributions}

$\mathrm{CH}$ and $\mathrm{BW}$ contributed to the study conception. $\mathrm{CH}, \mathrm{BW}$ and $\mathrm{TC}$ designed the survey, interpreted the data, and drafted and critically revised the manuscript. TC acquired the data. BW and TC helped in the quantitative analysis. All authors read and approved the final manuscript.

\section{Competing interests}

The authors declare that they have no competing interests.

\section{Publisher's Note}

Springer Nature remains neutral with regard to jurisdictional claims in published maps and institutional affiliations.

\section{Author details}

'Département des Sciences Sociales, Unité de Sociologie, University of Fribourg, Bd de Pérolles 90, CH-1700 Fribourg, Switzerland. ' FORS, Quartier UNIL-Mouline, University of Lausanne, Bâtiment Géopolis, 1015 Lausanne, Switzerland.

Received: 15 May 2017 Accepted: 13 August 2018

Published online: 28 January 2019

\section{References}

Aggarwal, R., Faccio, M., Guedhami, O., \& Kwok, C. C. Y. (2016). Culture and finance: An introduction. Journal of Corporate Finance, 41, 466-474.

Argyle, M., \& Furnham, A. (1998). The Psychology of money. London and New York: Routlege.

Beutler, I., \& Dickson, L. (2008). Consumer economic socialization. In J. J. Xiao (Ed. ), Handbook of consumer finance research (pp. 83-102). New York: Springer. Boltanski, L. (1966). Le bonheur suisse. Paris: Les Éditions de Minuit.

Brown, M., Henchoz, C., \& Spycher, T. (2018). Culture and financial literacy: Evidence from a within-country language border. Journal of Economic Behavior and Organization, 150, 62-85 https://doi.org/10.1016/j.jebo.2018.03.011.

Bühlmann, F., \& Tettamanti, M. (2007). Le statut de l'approche qualitative dans des projets de recherche interdisciplinaires. Recherches qualitatives, Hors Série (3), 191-213. 
Carroll, C. D., Rhee, B.-K., \& Rhee, C. (1994). Are there cultural effects on saving? Some cross-sectional evidence. The Quarterly Journal of Economics, 109(3), 685-699.

Carroll, C. D., Rhee, B.-K., \& Rhee, C. (1999). Does cultural origin affect saving behavior? Evidence from immigrants. Economic Development and Cultural Change, 48(1), 33-50. https://doi.org/10.1086/452445.

Chen, K. M. (2013). The effect of language on economic behavior: Evidence from saving rates, health behaviors, and retirement assets. American Economic Review, 103(2), 670-731. https://doi.org/10.1257/aer.103.2.690.

Christin, T. (2012). Endettement des jeunes adultes. Analyses complémentaires de l'endettement des jeunes adultes. Neuchâtel: Office fédéral de la statistique.

Chui, A. C. W., Titman, S., \& Wei, J. K. C. (2010). Individualism and momentum around the world. The Journal of Finance, 65(1), 361-392. https://doi.org/10. 1111/j.1540-6261.2009.01532.x.

Creswell, J. W. (2009). Research design. Qualitative, quantitative, and mixed methods approaches (3rd ed.). Thousand Oaks, CA: Sage.

Dell'Orto, G., \& Doyle, K. O. (2001). Poveri ma belli, meanings of money in Italy and in Switzerland. American Behavioral Scientist, 45(2), 257-271.

Eugster, B., Lalive, R., Steinhauer, A., \& Zweimueller, J. (2017). Culture, work attitudes and job search: Evidence from the Swiss language border. Journal of the European Economic Association, 15(5), 1056-1100. https://doi.org/10. 1093/jeea/jvw024.

Eugster, B., Lalive, R., Steinhauer, A., \& Zweimüller, J. (2011). The demand for social insurance: Does culture matter? The Economic Journal, 121, F413-F448. https://doi.org/10.1111/j.1468-0297.2011.02479.x.

Eugster, B., \& Parchet, R. (2013). Culture and taxes: towards identifying tax competition (Research Paper). University of Lausanne, Department of Economics: http://ux-tauri.unisg.ch/RePEc/usg/econwp/EWP-1339.pdf.

Eun, C. S., Wang, L., \& Xiao, S. C. (2015). Culture and R2. Journal of Financial Economics, 115(2), 283-303.

Falk, A., Becker, A., Dohmen, T. J., Enke, B., Huffman, D., \& Sunde, U. (2015). The nature and predictive power of preferences: Global evidence (Working Paper). University of Pittsburgh, Department of Economics: http://sticerd.lse. ac.uk/seminarpapers/psyc10112015.pdf

Fleury, S., \& Christin, T. (2015). Endettement et rapport à l'argent. Retrieved from Federal Statistical Office: http://www.bfs.admin.ch/bfs/portal/fr/index/ themen/20/02/blank/dos/04/02.html

Furnham, A., Kirkcaldy, B. D., \& Lynn, R. (1994). National attitudes to competitiveness, money, and work among young people: First, second, and third world differences. Human Relations, 47(1), 119-132.

Galland, O. ([1984] 2009). Les jeunes (Vol. 27). Paris: Éditions La Découverte, collection Repères.

Gentina, E., Butori, R., Rose, G. M., \& Bakir, A. (2013). How national culture impacts teenage shopping behavior: Comparing French and American consumers. Journal of Business Research, 67(4), 464-470.

Goldstein, H. (1991). Nonlinear multilevel models with an application to discrete response data. Biometrika, 78, 45-51. https://doi.org/10.2307/2336894.

Grinblatt, M., \& Keloharju, M. (2001). How distance, language, and culture influence stockholdings and trades. The Journal of Finance, 56(3), 1053-1073. https://doi.org/10.1111/0022-1082.00355.

Guin, B. (2017). Culture and household saving (Working Paper Series no. 2069). European Central Bank https://www.ecb.europa.eu/pub/pdf/scpwps/ecb. wp2069.en.pdf?a489f1abe4951dd2dbcb48562bc39b8c.

Guiso, L., Sapienza, P., \& Zingales, L. (2006). Does culture affect economic outcomes? Journal of Economic Perspectives, 20(2), 23-48. https://doi.org/10.1257/jep.20.2.23.

Guiso, L., Sapienza, P., \& Zingales, L. (2008). Trusting the stock market. The Journal of Finance, 63(6), 2557-2600. https://doi.org/10.1111/j.1540-6261.2008.01408.x.

Guiso, L., Sapienza, P., \& Zingales, L. (2013). The determinants of attitudes towards strategic default on mortgages. The Journal of Finance, 68(4), 1473-1515. https://doi.org/10.1111/jofi.12044.

Henchoz, C. (2008). Le couple, l'amour et l'argent. La construction conjugale des dimensions économiques de la relation amoureuse. Paris: L'Harmattan, collection Questions sociologiques.

Henchoz, C. (2013a). Les apprentis et l'argent. REISO Revue d'information sociale. Retrieved from http://www.reiso.org/spip.php?article3734

Henchoz, C. (2013b). Transmission de valeurs. Universitas, 1, 34-36.

Henchoz, C., Plomb, F., Poglia Mileti, F., \& Schultheis, F. (2016). Anthropological and sociological thoughts on financial education and economic practices of young people. International Journal of Business and Social Science, 7(1), 29-41.

Hox, J. J. (2010). Multilevel analysis. Techniques and applications (2nd ed.). New York: Routledge.
Kahneman, D. (2011). Thinking, fast and slow. New York: Farrar, Strass and Giroux. Khare, A. (2015). Influence of materialism and money attitudes on credit card use. International Journal of Business Competition and Growth, 4(1-2), 57-78.

Kim, J.-O., \& Mueller, C. W. (1978). Factor analysis: What it is and how to do it. Beverly Hills and London: Sage Publications.

Lamont, M. (1992). Money, morals, and manners: The culture of the French and the American upper-middle class. Chicago: University of Chicago Press.

Medina, J. F., Saegert, J., \& Gresham, A. (1996). Comparison of Mexican-American and Anglo-American attitudes toward money. Journal of Consumer Affairs, 30(1), 124-145. https://doi.org/10.1111/j.1745-6606.1996.tb00728.x.

Mitchell, T. R., \& Mickel, A. E. (1999). The meaning of money: An individualdifference perspective. The Academy of Management Review, 24(3), 568-578.

Mosimann, A. (2016). Les relations de couple. Enquête sur les familles et les générations 2013. Neuchâtel: Office fédéral de la statistique.

OECD. (2015). Household saving rates_forecasts. Retrieved from OECD.Stat: http://stats.oecd.org/Index.aspx?Queryld=51648

Parker, S., Hermans, C. M., \& Schaefer, A. D. (2008). Teens' attitudes towards clothing brands in general: A cross-cultural exploration. Journal of International Business and Economics Bulletin, 8(2), 110-116.

Polanyi, K. ([1944] 1983). La grande transformation. Paris: Gallimard.

Richins, M. L. (2004). The material values scales : Measurement properties and development of a short form. Journal of Consumer Research, 31(1), 209-219. https://doi.org/10.1086/383436.

Richins, M. L., \& Dawson, S. (1992). A consumer values orientation for materialism and its measurement: Scale development and validation. Journal of Consumer Research, 19(3), 303-316.

Roberts, J. A., \& Jones, E. (2001). Money attitudes, credit card use, and compulsive buying among American college students. Journal of Consumer Affairs, 35(2), 213-240. https://doi.org/10.1111/j.1745-6606.2001.tb00111.x.

Roberts, J. A., \& Sepulveda, C. J. M. (1999). Money attitudes and compulsive buying: An exploratory investigation ofthe emerging consumer culture in Mexico. Journal of International Consumer Marketing, 11(4), 53-74.

Schaefer, D. R., \& Dillman, D. A. (1998). Development of a standard email methodology: Results of an experiment. Public Opinion Quarterly, 62(3), 378-397.

Sutter, M., Kocher, M., Glätzle-Rüetzler, D., \& Trautmann, S. (2013). Impatience and uncertainty: Experimental decisions predict adolescents' field behavior. American Economic Review, 103(1), 510-531. https://doi.org/10.1257/aer.103.1.510.

Tang, L.-P. T., Arocas, R. L., \& Whiteside, H. D. (1997). Attitudes toward money and demographic variables as related to income and life satisfaction: USA vs. Spain. Paper presented at the annual conference of the International Association for Research in economic psychology, Valancia, Spain. https:// eric.ed.gov/?id=ED414870

Tang, L.-P. T., Furnham, A., \& Davis, G. M.-T. W. (2002). The meaning of money. The money ethic endorsement and work-related attitudes in Taiwan, the USA and the UK. Journal of Managerial Psychology, 17(7), 542-563.

Tang, L.-P. T., Furnham, A., \& Davis, G. M.-T. W. (2003). A cross-cultural comparison of the money ethic, the protestant work ethic, and job satisfaction: Taiwan, the USA, and the UK. International Journal of Organization Theory and Behavior, 6(2), 175-194.

Tang, L.-P. T., Sutarso, T., Ansari, M. A., Lim, V. K. G., Teo, T. S. H., Arias-Galicia, F., . . Tang, N. (2015). Monetary intelligence and behavioral economics across 32 cultures: Good apples enjoy good quality of life in good barrels. Journal of Business Ethics, 1-25. doi:https://doi.org/10.1007/s10551-015-2980-y.

Tang, T. L. P. (1992). The meaning of money revisited. Journal of Organizational Behavior, 13, 197-202

Vitell, S. J., Paolillo, J. G., \& Singh, J. J. (2006). The role of money and religiosity in determining consumers' ethical beliefs. Journal of Business Ethics, 64(2), 117-124.

Vitell, S. J., Singh, J. J., \& Paolillo, J. G. (2007). Consumers' ethical beliefs: The roles of money, religiosity and attitude toward business. Journal of Business Ethics, 73(4), 369-379.

Wernli, B., \& Henchoz, C. (2015). Les conséquences financières du départ du foyer parental. Une analyse longitudinale des données du Panel suisse de ménages. Swiss Journal of Sociology, 41(2), 311-328.

Yamauchi, K. T., \& Templer, D. I. (1982). The development of a money attitude scale. Journal of Personality Assessment, 46(5), 522-528. https://doi.org/10. 1207/s15327752jpa4605_14.

Zelizer, V. (2005). Culture and consumption. In N. J. Smelser \& R. Swedberg (Eds.), Handbook of economic sociology (pp. 331-354). Princeton: Princeton University Press. 